\title{
Mechanisms of constraint: a clinical inquiry of digital infrastructuring in municipalities
}

Jwan Khisro

Department of Applied IT, University of Gothenburg, Gothenburg, Sweden

Tomas Lindroth

Swedish Center for Digital Innovation, Department of Applied IT,

University of Gothenburg, Gothenburg, Sweden, and

Johan Magnusson

Swedish Center for Digital Innovation, Department of Applied IT, University of Gothenburg, Gothenburg, Sweden and School of Economics, Innovation and Technology, Kristiania University College, Oslo, Norway

\begin{abstract}
Purpose - The purpose of this study is to contribute to research concerning the role of digital infrastructure in digital government. This is done by answering the research question: how does digital infrastructuring constrain ambidexterity in public sector organizations?

Design/methodology/approach - The research is designed as a clinical inquiry in a large Swedish municipality, involving data collection in the form of interviews and internal documents. The method of analysis involves both exploring generative mechanisms in digital infrastructuring and theorizing on the findings based on previous literature.

Findings - The findings identify four generative mechanisms through which stability and change in digital infrastructuring constrain ambidexterity in terms of both efficiency (exploitation) and innovation (exploration).

Research limitations/implications - This study's limitations are related to international and intersectoral transferability and risks associated with its approach to clinical inquiry. The main implications are its contribution to the literature on how stability counteracts not only innovation but also efficiency and how change counteracts not only efficiency but also innovation.

Practical implications - This study identifies clear generative mechanisms that should be avoided by managers striving for digital government, and it offers clear recommendations for said managers regarding how to avoid them.

Social implications - This study offers implications for national-level digital infrastructure policy and contributes to efforts to increase the capabilities of digital government.

Originality/value - As two of the four identified generative mechanisms are novel contributions, this study offers a concrete addition to existing research. This study has resulted in factual change in the studied organization as well as at the national level through successful dissemination of the findings for both policy and practice in other public sector organizations.
\end{abstract}

Keywords Ambidexterity, Digital government, Digital infrastructure, Digital infrastructuring

Paper type Research paper

(C) Jwan Khisro, Tomas Lindroth and Johan Magnusson. Published by Emerald Publishing Limited. This article is published under the Creative Commons Attribution (CC BY 4.0) licence. Anyone may reproduce, distribute, translate and create derivative works of this article (for both commercial and non-commercial purposes), subject to full attribution to the original publication and authors. The full terms of this licence may be seen at http://creativecommons.org/licences/by/4.0/legalcode

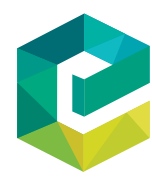

Received 20 January 2021

Revised 30 March 2021

29 April 2021

6 June 2021

8 June 2021

Accepted 14 June 2021

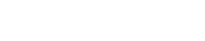




\section{Introduction}

As public organizations become increasingly dependent on digital technologies to facilitate value creation (Cordella and Paletti, 2018; Panagiotopoulos et al., 2019), digital infrastructure, here understood in line with Bowker et al. (2010) as a set of enabling, pervasive and boundary-spanning resources for digital activities, is becoming paramount for digital government (Janssen et al., 2009; Rose et al., 2018). At the same time, there have been numerous reports highlighting the public sector's tendency to under-invest in modernization of digital infrastructure (TBMV, 2018; RR, 2018). Without a continuous and purposive modernization of the digital infrastructure, the public sector will risk significant opportunity costs as its digital capabilities deplete over time (Rolland et al., 2018; Wimelius et al., 2021).

According to Tilson et al. (2010), digital infrastructure is different from other forms of infrastructure as it is built on a set of technologies endowed with unique characteristics. As the digital is programmable, reproducible and generative (Yoo et al., 2010), building and maintaining digital infrastructure has unique characteristics and challenges (Montealegre et al., 2019). This has consequences; although it can help organizations achieve their objectives, digital infrastructure simultaneously constrains organizations.

Tilson et al. (2010) provide insight into how digital infrastructure simultaneously constrains and facilitates organizations by identifying two key contradictory tensions: change versus stability and control versus autonomy. In addition to these two tensions, organizational ambidexterity (March, 1991) offers a theoretical lens to understand the development of digital infrastructure over time. Built on the core contradiction of exploitation versus exploration, organizational ambidexterity identifies the need for dynamic balancing of these parallel activities for the long-term success of the organization (Luger et al., 2018).

The information infrastructure stream of research has dominated previous research into digital infrastructure (Hanseth et al., 2012). Researchers aligned with this school have approached the notion of infrastructure from the perspective of Bowker and Star (2000), studying the development of technical standards, their diffusion and their resistance to change. In response to a perceived lack of research, Karasti et al. (2010) have proposed a turn toward performativity and practice within digital infrastructure. Instead of focusing on infrastructure and industries per se, these studies (Karasti and Blomberg, 2018) instead focus on the process and practice of infrastructuring in single organizations. This school aligns with the emerging tradition of digital infrastructuring studies conducted at the organization level, to which we strive to contribute.

Our study addresses the following question:

Q1. How does digital infrastructuring constrain ambidexterity in public sector organizations?

The study is operationalized through a clinical inquiry (Schein, 1987) of digital infrastructuring in a large Swedish municipality. As we worked closely with actors in the municipality, actively aiding them in the improvement of their digital infrastructuring, we were provided full access to multiple types of data.

We contribute to research through answering the calls for research on the "tension between digitally enabled flexibility and the constraints imposed by prior investments" (Tilson et al., 2010, p. 753) as well as how ambidextrous digital infrastructures change over time (Montealegre et al., 2019). In addition, we contribute to the stream of research on technological renewal in the public sector (Wimelius et al., 2021) with a focus on how infrastructuring constrains ambidexterity. Finally, we contribute to the emerging stream of 
research on the role of ambidexterity in digital government (Magnusson et al., 2020b; Cannaerts et al., 2019). We also contribute to practice through a validated model of how managers can avoid the constraining effects of digital infrastructure.

Mechanisms of

The paper is organized as follows. After the introduction, we present the preliminary findings regarding digital infrastructure and organizational ambidexterity and then the theoretical framing of ambidextrous digital infrastructure. After this, we present the method, elaborating on the clinical study and subsequent analysis of findings. This is followed by the results, with which we present four generative mechanisms involved in constraint digital infrastructuring and how these constrain ambidexterity. We end with a discussion and conclusions.

\section{Precursory findings and theoretical framing}

Digital infrastructure and infrastructuring

As noted in the Introduction, previous research into digital infrastructure has been dominated by the information infrastructure school (Hanseth et al., 2012). Such researchers have approached the notion of infrastructure from the perspective of Star (Bowker and Star, 2000; Star, 1999), studying infrastructure in relation to, for example, technical standards, flexibility and inertia (Hanseth et al., 2006; Hanelt et al., 2020). This theorization characterizes digital infrastructures as open to different users, interconnected with numerous modules and systems, constantly and dynamically evolving and shaped by existing systems and practices (Karasti and Blomberg, 2018).

Digital infrastructures are primarily approached as analytical constructs in the literature. They are distributed and embedded in a number of both social and material layers, and it is impossible to strip them away from these layers. As such, infrastructures are fundamentally relational, emerging in situ with organized practices connected to particular activities (Bowker and Star, 2000). This emergent perspective resists infrastructural design and topdown governance. As noted by Star (1999), it seems like nobody is really in charge of infrastructures, and they often become visible only when they break down.

The nature of infrastructures as emerging has become a focus in recent years, inspiring studies of infrastructures in-the-making through the lens of performativity (Star and Bowker, 2002; Montealegre et al., 2019). The notion of performativity focuses on how relations and boundaries between human actors and technologies are not clear-cut or fixed, but enacted. "Infrastructuring," as a verb, underlines the blurred boundaries between phases of development, implementation, use and maintenance (Karasti et al., 2010). Infrastructuring highlights the ongoing, provisional and contingent work that goes into working on infrastructures. Studies of infrastructuring shed light on the "invisible" work of infrastructures (Star, 1999). Despite being an emergent research perspective within digital infrastructure, there is still a dearth of research on digital infrastructuring (Karasti and Blomberg, 2018).

\section{Organizational ambidexterity}

Organizational ambidexterity, here understood in line with Raisch and Birkinshaw (2008, p. 375) as the "organization's ability to be aligned and efficient in its management of today's business demands while simultaneously being adaptive to changes in the environment [...]" has experienced a surge of scholarly interest during the past decade (Peng, 2019). Compared to early contributions such as March (1991) there have been at least three major additions to organizational ambidexterity during the past couple of years.

First, researchers such as Zimmermann et al. (2018) have identified the need to shift from a design perspective to an enactment perspective in the study of ambidexterity. As argued in their study of innovation initiatives, Raisch and Birkinshaw (2008) as well as 
Zimmermann et al. (2018) find that previous research has primarily addressed how organizations can be designed to achieve ambidexterity. Zimmermann et al. (2018) and Cannaerts et al. (2019) argue that instead of a top-down design perspective, research should address issues related to control enactment.

Second, studies such as those of Luger et al. (2018) and Magnusson et al. (2020b) call for a dynamic perspective on ambidexterity. Thus, ambidexterity should be seen not as a state, but as a process. The underlying assumption of this stream of research is that organizations never achieve ambidexterity, but that ambidexterity is a trait of organizations.

Third, studies such as those of Heracleous et al. (2019) and Montealegre et al. (2019) identify the historic path dependencies of ambidextrous balance and balancing. In their longitudinal study of NASA's ambidexterity, Heracleous et al. (2019) find that analysis of past decisions offers insight into current balancing practices.

Despite the fact that the majority of previous research intended to develop and use the organizational ambidexterity perspective has been directed toward the private sector, recent contributions, such as those of Cannaerts et al. (2019), Smith and Umans (2015); and Peng (2019), have demonstrated the transferability of ambidexterity to the public sector. Public sector organizations are innately different from private sector organizations (Gil-Garcia and Martinez-Moyano, 2007), yet they both need to work toward short-term efficiencies (as a result of limited funding) and long-term innovation (as a result of fluctuations in demands from citizens). At their core, efforts to achieve continuous relevance over time are common to all types of organizations, including those in the public sector, and in this context, ambidexterity offers a concrete and proven analytical lens (Peng, 2019).

\section{Theoretical framing: ambidextrous digital infrastructuring}

The brief overview of precursory findings from the fields of digital infrastructure and ambidexterity allows us to pose four assumptions to guide this study as follows:

(1) Organizational ambidexterity is not a state, but a dynamic process (Luger et al., 2018).

(2) Digital infrastructuring is a dynamic process (Montealegre et al., 2019).

(3) Ambidextrous digital infrastructuring entails a combination of design and enactment in the pursuit of dynamic balancing of efficiency and innovation (Zimmermann et al., 2018).

(4) Ambidextrous digital infrastructuring is not ahistorical; it is associated with significant path dependencies that develop over time (Heracleous et al., 2019).

In addition to the four assumptions, we use the foundational work on digital infrastructure of Tilson et al. (2010), who identified two contradictory tensions in the context of this infrastructure: change and control. In this setting, change refers to the opposing traits of stability and change in digital infrastructure. Digital infrastructure needs a certain amount of stability in the installed base as well as a certain amount of flexibility in terms of generative functionality, which can be achieved through the integration of new services with legacy services. There are inherent interdependencies and apparent tradeoffs between stability and change.

The second contradiction identified by Tilson et al. (2010) is that of control. The authors focus on the opposing logics of centralized and distributed (decentralized) control. Although the locus of control is an important and relevant issue that has been studied in depth in the past (Cram et al., 2016), we posit that Tilson et al's (2010) contradiction of control may be supplemented by the parallel objectives of efficiency (exploitation) and innovation 
(exploration), which were elaborated in studies of organizational ambidexterity (for an overview of the equation of exploitation/efficiency and exploration/innovation, see Benner and Tushman, 2003 and Magnusson et al., 2020a). In other words, this study integrates the ambidextrous contradiction of efficiency versus innovation as a substitute for the locus of control, resulting in the matrix shown in Figure 1.

As seen in Figure 1, digital infrastructuring activities fall into one of four categories, depending on the categorization of the intent and the function of the activity as such. Previous research clearly identifies optimal patterns in terms of fit for each quadrant. For instance, efficiency is expected to benefit from stability and be counteracted by change, and innovation is expected to benefit from change and be counteracted by stability. However, on the basis of recent findings from the field of digital transformation (Wimelius et al., 2021), we posit that there may be situations in which efficiency is counteracted by stability and innovation is counteracted by change.

\section{Method}

The methodological approach of this study is guided by the clinical perspective introduced by Schein (1987), in which the researcher is actively engaged in the organization under study and is often requested to solve a particular problem. In the case addressed in this study, the research team was asked by the municipality of Sundsvall, Sweden, to aid in the execution of a new digital agenda launched in 2018. The municipality is located in the middle of Sweden, and it has a total of 100,000 citizens, 9,000 employees, and an operating budget of $€ 600 \mathrm{~m}$ (Ekonomifakta, 2021). The municipality expressed a direct need for new insight, which they believed could be only through involvement in research. A semi-structured contract was put in place, balancing the aspirations of the researchers (to gain empirical access, funding and freedom to operate) and the organization (to solve practical issues through learning and research insights). This paper reports on one of five assignments specified in the contract. Funding was shared; the funding from the municipality was complemented by university funding to allow the researchers increased freedom to operate.

The researchers were internally marketed as key players through seminars. This resulted in both legitimacy (both frontstage and backstage, as argued by Goffman, 1959) and what Schein (1987) refers to as "wandering," meaning that the researchers were involved with issues and aspects of the organization that were not part of the original intent

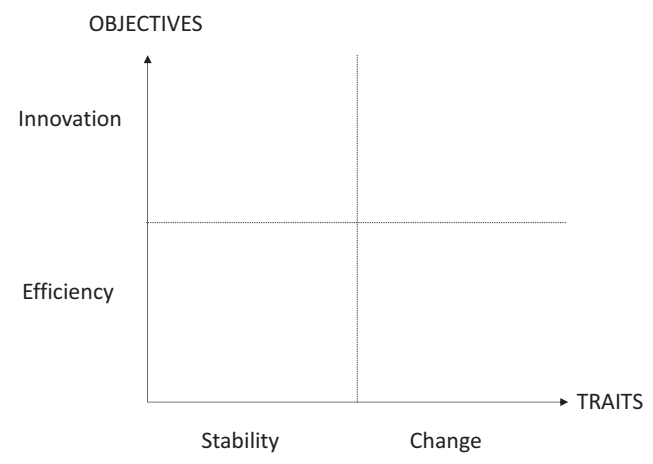

Source: Adopted from Tilson et al. (2010) and Magnusson et al. (2020a)
Mechanisms of constraint

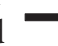


of the research. The researchers continually communicated with the steering group to ensure that there was support for the drift. As noted by Schein (1987), one of the most critical caveats of the clinical approach is the need to manage expectations. As the researchers were actively involved in the municipality, efforts were made to communicate a joint understanding of how the researchers' involvement was different from that of, for example, a consultant. The research process involved the steps presented in Figure 2.

Data collection was conducted through iterative polling for internal documents relevant to the assignment. In addition, 21 semi-structured interviews with individuals considered to be instrumental in the management of digital infrastructure were conducted following snowball sampling (Hennink et al., 2011). The interviews were conducted through Skype owing to the pandemic, sound recorded and transcribed. As this was part of a larger ongoing research project, we used data with relevance to the research question that had been collected previously. This involved polling from a body of 38 interviews and 100 documents.

The analysis consisted of two main parts. First, we sensitized ourselves to the case by reading and re-reading both the secondary and primary data (Elo et al., 2014). Following this, we performed axial and thematic coding (Hennink et al., 2011) of the interviews, working inductively to derive first- and second-order constructs that would support us in answering the research question. We were inspired by Henfridsson and Bygstad's (2013) analytical work related to generative mechanisms.

As noted by Schein (1987), validation is often equated with the impact of the interventions that constitute the research process. In the case of the municipality, the results were instrumental for implementing a new approach to digital infrastructure management. At present, the organization is implementing the major recommendations from the study. In parallel with this, a dialogue was initiated with the association for municipalities in Sweden to scale the recommendations to the entire population of 290 municipalities. In addition, we used the findings were used to initiate the design of a new digital solution to support municipalities in implementing the recommendations. There has been significant interest in the project shown by society in general, with interviews in national media, over 30 keynotes on conferences and invitations to several policy working groups. In addition, several contributions to the scientific community through publications such as references to authors' previous publications have been made.

\section{Results: ambidextrous digital infrastructuring}

We identify four generative mechanisms of digital infrastructuring that constrain ambidexterity in the case organization. These are summarized in Figure 3.

Contrary to previous research (Tilson et al, 2010) we found evidence of not only the constraining effects of stability on innovation and change for efficiency but also the constraining effects of stability on efficiency and change on innovation. These four constraining mechanisms are presented sequentially and organized according to the two traits (stability and change) (Figure 4).

\section{How stability constrains ambidexterity: silence and reactivity}

Stability constrains efficiency (Mechanism 1: silence) through sustaining and maintaining systems that have shifted from facilitating to constraining the organization in its efforts to achieve objectives:

Figure 2.

Research design
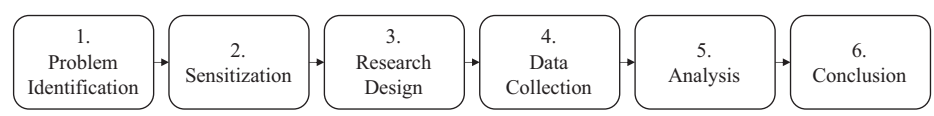
We would need to work to create better prerequisites both for realizing the benefits and for being able to work with digitalization in an efficient manner. I mean that it becomes efficient to work with digitalization, and long-term efficient (i.e., smart governance of digitalization) (IT Coordinator).

The organization's capability for cost-efficient maintenance of systems, coupled with a lack of control and an absence of audits or decision criteria for decommissioning [1], leads to narrowing of the required competence base for coworkers in IT:

I think there are a lot of enterprise systems that we could decommission. All the enterprise systems are so specific and have their own database. I think that we need to lift our gaze and look at the complete picture (IT Strategy Officer).

Personnel resources are directed toward technologies that have long since become obsolete in the market (e.g. local HR and finance systems), preventing staff turnover and making recruitment more difficult. Decreased attractiveness as an employer (owing to antiquated

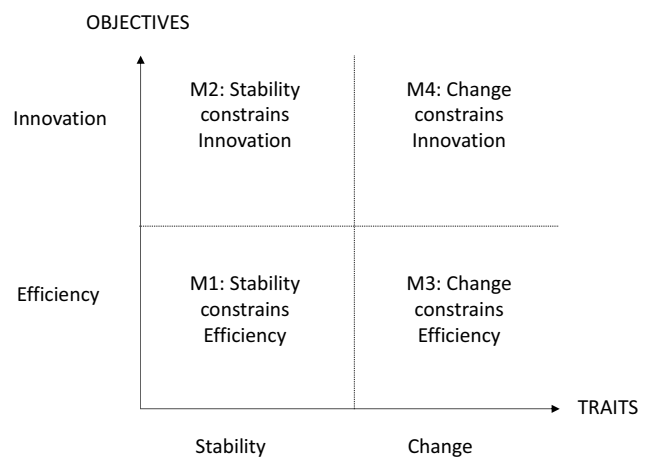

Figure 3.

Overview of the results for ambidextrous digital infrastructuring

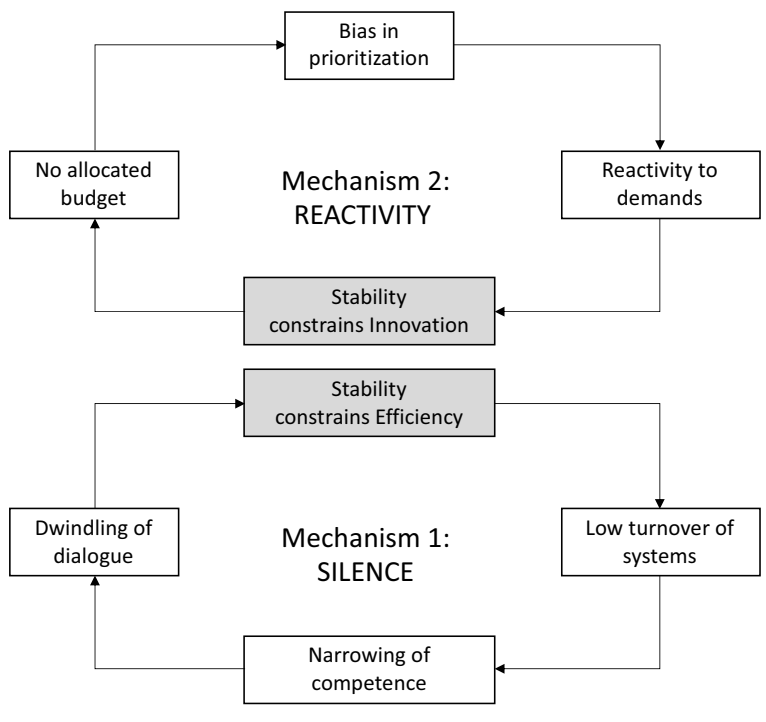

Figure 4.

Constraining mechanisms of stability: silence and reactivity 
technology stacks such as electronic data interchange) leads to a decreased ability to attract 16,1 new talent. As the competence of coworkers narrows, the ability for a true dialogue with the business (i.e. one built on the possibilities of digital technologies rather than the existing installed base) is decreased:

Within HR, we have control over operations and maintenance (i.e., we handle what we have, but we have less knowledge and competence and drive within development). So, we are good at maintaining earlier solutions and worse in terms of developing new solutions. Nobody works "outside of the box" (HR Strategy Officer).

As a result, there is a decrease in the exploitation of existing opportunities; the organization fails to swiftly meet new technological developments (e.g. artificial intelligence, microservices), and so the effect and benefits of said new technologies is lost. Continuous improvements also have no effect, and all the focus is shifted toward sustaining the installed base.

Stability constrains innovation (Mechanism 2: reactivity) through the practice of allocating general IT budgets that include funding for both maintenance and development. When total IT costs are kept as low as possible and are expected to decrease over time, stability results in decreasing returns on maintenance efficiencies, and the room for development shrinks over time:

The harsh economic reality makes it difficult to prioritize funds for development. But the greatest challenge lies in the understanding of what we need to prioritize [....] I would like to see more financial resources for us to shift gears and develop/digitalize faster (Politician).

Shrinking development budgets lead to risk avoidance in the selection and prioritization of digital initiatives, meaning the appearance of a tendency to prioritize initiatives with clear, short-term, rationalization benefits (e.g. robotic process automation and other automation initiatives). This is motivated by the notion that, in the long run, rationalization will create increased room for development. However, the result is an imbalance between the organization's demand for new solutions and the IT organization's ability to deliver. In this context, reactivity, as opposed to proactivity, in meeting business demands becomes prominent (Figure 5):

Figure 5.

Constraining mechanisms of change: impact and shadow
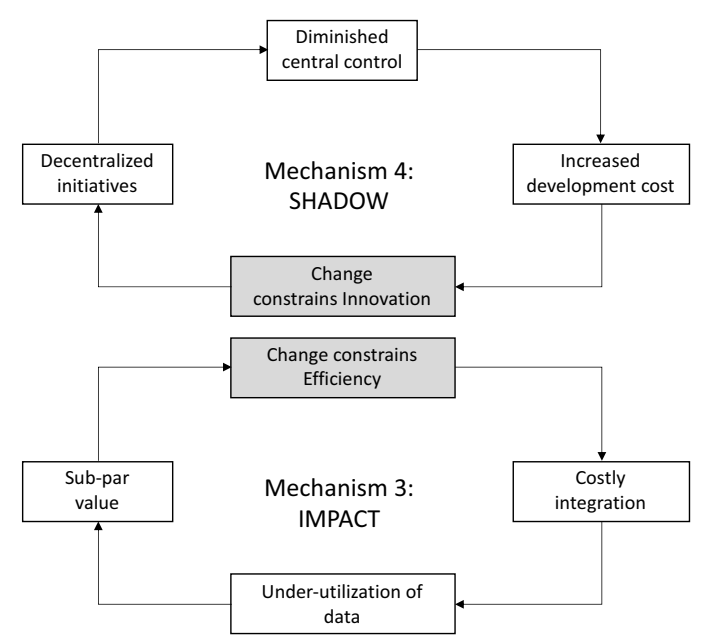
The problem is that you are too slow, you are reactive, you are far behind. The weakness is that what you have is too old and you do not keep up with the pace of change (Chief Technology Officer).

How change constrains ambidexterity: impact and shadow. Change constrains efficiency (Mechanism 3: impact) by decreasing the financial possibility for large initiatives related to integration (e.g. application programming interface strategies, micro-service platforms, data lakes). Development over time leads to increased lock-in, path dependencies and changes to redundant solutions and those lacking integration:

Integration between systems is the most critical [outcome]. We need to have a modern integration platform (i.e., a data broker); we need to have a system that can scale to the entire business and connect systems in a simple, robust and smart manner. That is what we are missing out on (IT Architect).

The cost per integration continues to be high as a consequence of non-modern technology stacks (e.g. enterprise application integration and other non-service oriented architecture solutions), which counteract initiatives that require integration (such as cross-functional initiatives). This, in turn, leads to systemic under-utilization of data, with consequences in the form of manual routines and a lack of ability to execute new digital initiatives with clear benefits for the organization owing to insurmountable integration costs. The result is that the digital initiatives that are prioritized deliver sub-par benefits in relation to the costs, which negatively impacts confidence in digital solutions and the organization's propensity for adoption:

The business does not understand the value and worth of information, but can only think in terms of functionality [....] I think about the old systems you have as the digital heritage. The systems are great at what they can do, but now, reality and the way we work have changed, and now we want data in an entirely new manner. But these systems lock the business-critical data that is a key resource into advances in terms of innovation and automation. We have a bunch of enterprise systems, but they cannot collaborate. Therefore, we have to keep them in multiple versions or generations and maintain them in order to access old data (IT Strategy Officer).

Change constrains innovation (Mechanism 4: shadow) through a lack of centralized governance and decentralization of mandates for digital initiatives. The consequence of this is twofold: first, increased coordination cost, and second, a lack of insight into the changing digital infrastructures that are necessary for development initiatives (i.e. application programming interface platforms, low-code platforms):

The digital infrastructure is very fragmented; it is not stable nor flexible. The initiatives have not been coordinated, and different parts of the organization have done their own things. This results in a situation where we have different IT environments and partly different technical solutions (IT Service Manager).

Less centralized control increases the risks associated with redundancies and counterstrategic choices during prioritization. This, in turn, leads to even higher development costs, as new solutions require secondary changes to the existing infrastructure. The development costs further counteract pace and risk appetite, as the funding is handled as a decentralized operating expense:

The municipality wants to avoid mistakes and are really careful, minimizing risk, decreasing costs all the time, so innovation doesn't really fit. It is all about risk avoidance, all the time (IT Strategy Officer).

Mechanisms of constraint 
TG

16,1

90

\section{Discussion}

We summarize the four identified mechanisms in a matrix with objectives (efficiency or innovation) and traits (stability or change) as dimensions (Figure 6).

As seen in Figure 6, the way that digital infrastructuring was enacted constrains the organization in terms of reaching the objectives of efficiency and innovation. Through an assemblage of practices associated with funding (e.g. allocation of funds for development budgets, loci of funding) and decision-making (e.g. prioritization, recruitment), we find how digital infrastructuring simultaneously constrains and facilitates ambidexterity (Cannaerts et al., 2019). Given that ambidexterity was previously identified as a prerequisite for digital government (Peng, 2019), the digital infrastructuring in this study is counter-productive to the long-term performance of the organization (Raisch and Birkinshaw, 2008). Seen in isolation, each activity may seem logical and even aspirational (e.g. a decentralization of mandate, focus on efficiency gains, low turnover of systems), but when viewed from a long-term perspective, sub-optimizations become apparent.

These adverse constraining effects are manifested through generative mechanisms (Henfridsson and Bygstad, 2013). As digital government ushers in the need for new capabilities from both the organization and digital infrastructure (Janssen et al., 2009), a sole focus on short-term efficiency gains may be detrimental to long-term performance. The silence, reactivity, shadow and impact mechanisms offer a stark contrast to what Janssen and van der Voort's (2016) term adaptive governance. Rather than instilling the organization with more agile capabilities (Mergel et al., 2018), the generative mechanisms presented here counteract agility and adaptivity.

The effect of this is that both efficiency and innovation are negatively impacted by both traits (stability and change) by digital infrastructuring. Although in the previous literature stability negatively impacts solely innovation, this study found that it also has a detrimental effect on efficiency; the practices associated with system maintenance and operations gradually decrease the necessary competence and dialogue. In this setting, new technologies that are highly relevant and efficient (e.g. artificial intelligence, robotic process automation) may run the risk of not being adopted owing to obsolete technology stacks and a lack of competence and dialogue. In other words, the stability of digital infrastructuring limits the digital options for an organization and significantly counteracts the ambitions of digital government (Cannaerts et al., 2019; Magnusson et al., 2020a).

Figure 6.

Constraining mechanisms of ambidextrous digital infrastructuring

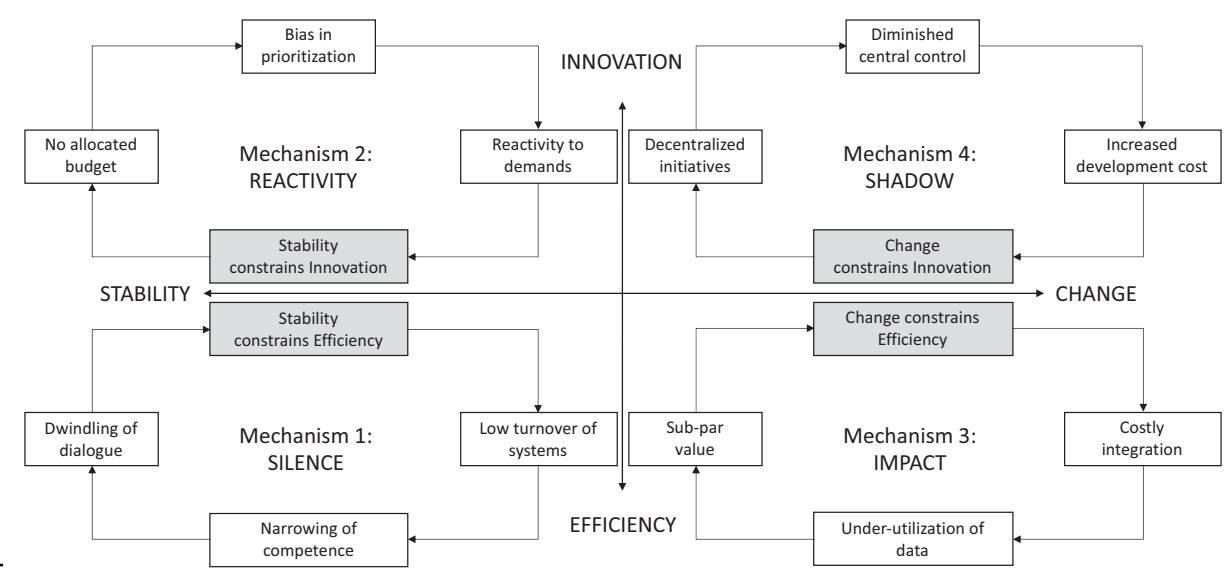




\section{Conclusion}

In this study, we have answered the research question - How does digital infrastructuring constrain ambidexterity in public sector organizations? - through a clinical inquiry study of a large Swedish municipality. The study finds that the traits of stability and change in digital infrastructure constrain ambidexterity in the organization through four generative mechanisms. We identified how stability in digital infrastructuring constrains not only innovation (exploration) but also efficiency (exploitation), and how change constrains not only efficiency but also innovation. These findings - primarily the mechanisms through constraint which stability constrains efficiency and change constrains innovation - constitute a contribution to the research on digital infrastructure, which has previously been focused on how change facilitates innovation and how stability facilitates efficiency.

This study contributes to research in three main ways. First, the identified constraining impact of digital infrastructure stability on efficiency and digital infrastructure change on innovation offers a concrete contribution to the digital infrastructure literature. Previous research has primarily focused on the intuitive negative impacts of change on efficiency (e.g. if the platform is not stable, development will suffer) and stability on innovation (e.g. inertia negatively influences exploration). Our contribution improves the understanding of the constraining effects of digital infrastructure (Tillson and Lyytinen, 2010). Second, by shifting our focus to infrastructure as a practice (infrastructuring), we provide further inspiration for this empirical stance in the study of digital infrastructure (Karasti and Blomberg, 2018). Third, our choice to use clinical inquiry as a method for engaging with the organization may offer inspiration for the e-government community. The clinical inquiry approach is attracting new interest from academia, as reported by Baskerville et al. (2020), and it can have significant benefits for research if the risks are managed properly (Schein, 1987).

This study offers one main contribution to practice (i.e. management): managers should consider the four generative mechanisms as summarized in Figure 6 and assess how they appear in their own organizations. To support this process, we have created a selfassessment tool found in Appendix 1. If managers find evidence of the mechanisms in their own practice, we recommend that they consider revising their digital infrastructuring. As we have shown, practices associated with the allocation of budgets, distribution of decision rights and so on may be detrimental to the long-term achievement of digital government. If the managers work in organizations that aspire for digital government, the generative mechanisms should adamantly be avoided and subsequently offer a basis for governance redesign. In the organization in focus for this paper, the clinical inquiry resulted in a re-vamp in IT governance and the setup for how IT is provisioned internally, as well as direct changes where the governance of infrastructure was integrated into the overarching corporate governance of the municipality. The municipality acted swiftly following the clinical inquiry to alleviate the shortcomings of the digital infrastructuring, with direct positive results.

This study offers one main contribution to policy: owing to the increased emphasis on national digital infrastructures, at least in the Swedish setting, there is a need for a more foundational understanding of not only the affordances of digital infrastructure but also the constraints. Future policies should use the findings of this study to push for new investments in national digital infrastructure that avoid delimiting organizational ambidexterity. This would involve changing, for example, accounting rules and regulations for municipal investments to better cater to organizational ambidexterity. A first step toward this would be to create an oversight of digital infrastructuring in all municipalities, to have sufficient data to drive policy in the right direction. 
We identify three potential projects for future research. First, we propose a projected targeted at an overarching understanding of the current national state of digital infrastructuring. At present, we are working on operationalizing this using inspiration from the analytical framework presented in this paper, packaged into a digital service that in parallel will offer support public sector organizations and collect the necessary data to inform policy and strengthen research. Second, we propose a project where the pace of infrastructural modernization and renewal (Wimelius et al., 2021) can be measured and used as an independent variable for studies of digital innovation. This would allow us to increase our understanding of the role of digital infrastructure change in digital innovation, an issue that so far has been gravely overlooked by previous research. Provided the strong interest in digital innovation within the public sector, we believe this study to be of value to both research and practice. Third and final, we propose a project directed toward the role of managers in digital infrastructuring. In the current study, we see indications of different personal approaches weighing in on how digital infrastructuring is enacted in the organization. The proposed project would build on expanding our understanding of the role of the manager, using inspiration from studies such as resource orchestration theory (Sirmon et al., 2011) and its adaptation for management practice.

There are two main limitations of our study. First, as this is a study of one organization in Sweden, we are aware of the potential limits to transferability. Studies of public sector organizations are, as noted by Bannister (2007), laden with such limits due to the particularities of the institutional framing of each country's public sector. However, as all the elements of the generative mechanisms are organizational, rather than national, in nature, we argue that the study still provides transferable insight for public sector organizations in other countries as well as other sectors. The empirical identification of sub-par investments into digital infrastructure is cross-national (TBMV, 2018; RR, 2018), whereby at least the problem can be seen as commonplace within the public sector. Second, the choice to conduct the study as a clinical inquiry comes with certain caveats, as mentioned in the method section. We have tried to counteract these potential risks with transparency and clarity. Also, we leaned on the credibility assessment promoted by Schein (1987), according to which validation is equated with the adoption of new insights by the organization. Thus, we deem the national diffusion of the findings (described above) as a clear sign of validation from the public sector.

\section{Note}

1. In the audit performed as part of our larger study, only $5 \%$ of the total amount of systems (over 600 ) had established practices for decommissioning (i.e., a fixed date for assessment and/or decommissioning).

\section{References}

Bannister, F. (2007), "The curse of the benchmark: an assessment of the validity and value of e-government comparisons", International Review of Administrative Sciences, Vol. 73 No. 2, pp. 171-188, doi: 10.1177/0020852307077959.

Baskerville, R., Vom Brocke, J., Mathiassen, L. and Scheepers, H. (2020), "Special issue call for papers: clinical research from information systems practice", European Journal of Information Systems, available at: www.journalconferencejob.com/ejis-si-clinical-research-information

Benner, M.J. and Tushman, M.L. (2003), "Exploitation, exploration, and process management: the productivity dilemma revisited", Academy of Management Review, Vol. 28 No. 2, pp. 238-256, doi: 10.5465/amr.2003.9416096. 
Bowker, G.C. and Star, S.L. (2000), Sorting Things Out: Classification and Its Consequences, MIT press.

Bowker, G.C., Baker, K., Millerand, F. and Ribes, D. (2010), "Toward information infrastructure studies: ways of knowing in a networked environment", in Hunsinger, J., Klastrup, L. and Allen, M. (Eds), International Handbook of Internet Research, Springer, Dordrecht, Netherlands, pp. 97-117, doi: 10.1007/978-1-4020-9789-8_5

Cannaerts, N., Segers, J. and Warsen, R. (2019), “Ambidexterity and public organizations: a configurational perspective", Public Performance and Management Review, Vol. 43 No. 3, pp. 1-25, doi: 10.1080/15309576.2019.1676272.

Cordella, A. and Paletti, A. (2018), "ICTs and value creation in public sector: Manufacturing logic vs service logic", Information Polity, Vol. 23 No. 2, pp. 125-141.

Cram, W.A., Brohman, K. and Gallupe, R.B. (2016), "Information systems control: a review and framework for emerging information systems processes", Journal of the Association for Information Systems, Vol. 17 No. 4, Article 2, doi: 10.17705/1jais.00427.

Ekonomifakta (2021), "Sundsvall", available at: www.ekonomifakta.se/Fakta/Regional-statistik/Allalan/Vasternorrlands-lan/Sundsvall/ (accessed 1 September 2020).

Elo, S., Kääriäinen, M., Kanste, O., Pölkki, T., Utriainen, K. and Kyngäs, H. (2014), “Qualitative content analysis: a focus on trustworthiness", SAGE Open, Vol. 4 No. 1, doi: 10.1177/2158244014522633.

Gil-Garcia, J.R. and Martinez-Moyano, I.J. (2007), "Understanding the evolution of e-government: the influence of systems of rules on public sector dynamics", Government Information Quarterly, Vol. 24 No. 2, pp. 266-290, doi: 10.1016/j.giq.2006.04.005.

Goffman, E. (1959), The Presentation of Self in Everyday Life, Anchor Books, New York, NY.

Hanelt, A., Bohnsack, R., Marz, D. and Antunes Marante, C. (2020), "A systematic review of the literature on digital transformation: insights and implications for strategy and organizational change", Journal of Management Studies, Month, Vol. 58 No. 5, doi: 10.1111/ joms.12639.

Hanseth, O., Bygstad, B., Ellingsen, G., Johannessen, L.K. and Larsen, E. (2012), "ICT standardization strategies and service innovation in health care", Thirty Third International Conference of Information Systems, Orlando, December, pp. 16-19.

Hanseth, O., Jacucci, E., Grisot, M. and Aanestad, M. (2006), "Reflexive standardization: side effects and complexity in standard making", MIS Quarterly, Vol. 30, pp. 563-581.

Henfridsson, O. and Bygstad, B. (2013), "The generative mechanisms of digital infrastructure evolution”, MIS Quarterly, Vol. 37 No. 3, pp. 907-931, available at: www.jstor.org/stable/ 43826006

Hennink, M., Hutter, I. and Bailey, A. (2011), Qualitative Research Methods, SAGE Publications, London, CA, New Delhi, Singapore.

Heracleous, L., Yniguez, C. and Gonzalez, S.A. (2019), "Ambidexterity as historically embedded process: evidence from NASA, 1958 to 2016", The Journal of Applied Behavioral Science, Vol. 55 No. 2, pp. 161-189, doi: 10.1177/0021886318812122.

Janssen, M. and Van Der Voort, H. (2016), “Adaptive governance: towards a stable, accountable and responsive government”, Government Information Quarterly, Vol. 33 No. 1, pp. 1-5, doi: 10.1016/ j.giq.2016.02.003.

Janssen, M., Chun, S.A. and Gil-Garcia, J.R. (2009), "Building the next generation of digital government infrastructures", Government Information Quarterly, Vol. 26 No. 2, pp. 233-237.

Karasti, H. and Blomberg, J. (2018), "Studying infrastructuring ethnographically", Computer Supported Cooperative Work (CSCW), Vol. 27 No. 2, pp. 233-265, doi: 10.1007/s10606-017-9296-7.

Karasti, H., Baker, K.S. and Millerand, F. (2010), "Infrastructure time: long-term matters in collaborative development”, Computer Supported Cooperative Work (CSCW), Vol. 19 Nos 3/4, pp. 377-415, doi: 10.1007/s10606-010-9113-z. 
Luger, J., Raisch, S. and Schimmer, M. (2018), "Dynamic balancing of exploration and exploitation: the contingent benefits of ambidexterity", Organization Science, Vol. 29 No. 3, pp. 449-470, doi: $10.1287 /$ orsc.2017.1189.

Magnusson, J., Koutsikouri, D. and Päivärinta, T. (2020a), "Efficiency creep and shadow innovation: enacting ambidextrous IT governance in the public sector", European Journal of Information Systems, Vol. 29 No. 4, pp. 1-21, doi: 10.1080/0960085X.2020.1740617.

Magnusson, J., Päivärinta, T. and Koutsikouri, D. (2020b), "Digital ambidexterity in the public sector: empirical evidence of a bias in balancing practices", Transforming Government: People, Process and Policy.

March, J.G. (1991), "Exploration and exploitation in organizational learning", Organization Science, Vol. 2 No. 1, pp. 71-87, doi: 10.1287/orsc.2.1.71.

Mergel, I., Gong, Y. and Bertot, J. (2018), "Agile government: systematic literature review and future research”, Government Information Quarterly, Vol. 35 No. 2, pp. 291-298, doi: 10.1016/j. giq.2018.04.003.

Montealegre, R., Iyengar, K. and Sweeney, J. (2019), "Understanding ambidexterity: managing contradictory tensions between exploration and exploitation in the evolution of digital infrastructure", Journal of the Association for Information Systems, Vol. 20 No. 5, pp. 647-680, doi: 10.17705/1jais.00547.

Panagiotopoulos, P., Klievink, B. and Cordella, A. (2019), "Public value creation in digital government", Government Information Quarterly, Vol. 36 No. 4.

Peng, H. (2019), "Organizational ambidexterity in public non-profit organizations: interest and limits", Management Decision, Vol. 57 No. 1, pp. 248-261, doi: 10.1108/MD-01-2017-0086.

Raisch, S. and Birkinshaw, J. (2008), "Organizational ambidexterity: antecedents, outcomes, and moderators", Journal of Management, Vol. 34 No. 3, pp. 375-409, doi: 10.1177/0149206308316058.

Rolland, K.H., Mathiassen, L. and Rai, A. (2018), "Managing digital platforms in user organizations: the interactions between digital options and digital debt", Information Systems Research, Vol. 29 No. 2, pp. 419-443.

Rose, J., Flak, L.S. and Sæbø, Ø. (2018), "Stakeholder theory for the e-government context: framing a value-oriented normative core", Government Information Quarterly, Vol. 35 No. 3, pp. 362-374.

Schein, E. (1987), The Clinical Perspective in Fieldwork. Qualitative Research Methods, SAGE Publications, Thousand Oaks, CA, doi: 10.4135/9781412986137

Sirmon, D.G., Hitt, M.A., Ireland, R.D. and Gilbert, B.A. (2011), "Resource orchestration to create competitive advantage: breadth, depth, and life cycle effects", Journal of Management, Vol. 37 No. 5, pp. 1390-1412.

Smith, E. and Umans, T. (2015), "Organizational ambidexterity at the local government level: the effects of managerial focus", Public Management Review, Vol. 17 No. 6, pp. 812-833, doi: 10.1080/ 14719037.2013.849292.

Star, S.L. (1999), "The ethnography of infrastructure", American Behavioral Scientist, Vol. 43 No. 3, pp. 377-391, doi: 10.1177/00027649921955326.

Star, S.L. and Bowker, G.C. (2002), "How to infrastructure", in Lievrouw, L.A. and Livingstone, S. (Eds), Handbook of New Media - Social Shaping and Consequences of ICTs, SAGE Publications, London, UK, pp. 151-162.

Tilson, D., Lyytinen, K. and Sorensen, C. (2010), "Desperately seeking the infrastructure in is research: conceptualization of 'digital convergence' as co-evolution of social and technical infrastructures", 43rd HI International Conference on System Sciences, Honolulu, HI, IEEE, pp. 1-10, doi: 10.1109/ HICSS.2010.141

Wimelius, H., Mathiassen, L., Holmström, J. and Keil, M. (2021), "A paradoxical perspective on technology renewal in digital transformation", Information Systems Journal, Vol. 31 No. 1, pp. 198-225, doi: 10.1111/isj.12307. 
Yoo, Y., Henfridsson, O. and Lyytinen, K. (2010), "Research commentary - the new organizing logic of digital innovation: an agenda for information systems research", Information Systems Research, Vol. 21 No. 4, pp. 724-735, doi: 10.1287/isre.1100.0322.

Zimmermann, A., Raisch, S. and Cardinal, L.B. (2018), "Managing persistent tensions on the frontline: a configurational perspective on ambidexterity", Journal of Management Studies, Vol. 55 No. 5, pp. 739-769, doi: 10.1111/joms.12311.

\section{Further reading}

Hanseth, O., Monteiro, E. and Hatling, M. (1996), "Developing information infrastructure: the tension between standardization and flexibility”, Science, Technology, and Human Values, Vol. 21 No. 4, pp. 407-426, doi: 10.1177/016224399602100402.

RR (2019), "Föråldrade it-system - hinder för en effektiv digitalisering (RiR 2019:28), in Swedish", available at: www.riksrevisionen.se/rapporter/granskningsrapporter/2019/foraldrade-it-systemhinder-for-en-effektiv-digitalisering.html

TBMV (2016), "Accelerating the mission: recommendations for optimizing federal technology cost and value in the age of FITARA", available at: www.actiac.org/accelerating-missionrecommendations-optimizing-federal-technology-cost-and-value-age-fitara

\section{Appendix 1: Self-assessment template}

In order to support the utilization of the research findings of this study, we have designed a selfassessment template to allow managers involved in digital infrastructuring to identify drawbacks in their existing practices.

\section{Question}

\section{Assessment: 1. I do not agree - 6. I fully agree}

How stability in digital infrastructuring constrains efficiency.

We have a low pace of turnover of systems in our digital infrastructure.

$\begin{array}{llllll}1 & 2 & 3 & 4 & 5 & 6\end{array}$

We have a narrowing competence over time in the personnel responsible for maintaining and developing our digital infrastructure.

$$
\begin{array}{lllllll}
1 & 2 & 3 & 4 & 5 & 6
\end{array}
$$

We see a dwindling of dialogue between the maintenance and development of digital infrastructure and the business.

$\begin{array}{llllll}1 & 2 & 3 & 4 & 5 & 6\end{array}$

Average 1

2. How stability in digital infrastructuring constrains innovation.

We lack sufficient budgets allocated to digital innovation.

$\begin{array}{llllll}1 & 2 & 3 & 4 & 5 & 6\end{array}$

We have a tendency to prioritize increased efficiency at the expense of higher-risk digital innovation.

$$
\begin{array}{llllll}
1 & 2 & 3 & 4 & 5 & 6
\end{array}
$$

We are reactive in the meeting of new demands from business.

$$
\begin{array}{llllll}
1 & 2 & 3 & 4 & 5 & 6
\end{array}
$$

Average 2

3. How change in digital infrastructuring constrains efficiency.

We devote a significant portion of our maintenance budget to integration solutions.

3
4
5
6

2 
We under-utilize the data that we store in our digital infrastructure.

16,1

$\begin{array}{llllll}1 & 2 & 3 & 4 & 5 & 6\end{array}$

Digital initiatives suffer from delivering sub-par value, i.e. not reaching the aspired benefits realization.

$\begin{array}{llllll}1 & 2 & 3 & 4 & 5 & 6\end{array}$

Average 3

4. How change in digital infrastructuring constrains innovation.

Digital initiatives are primarily decentralized, i.e. the bulk of funding for digital infrastructure is decentralized.

$\begin{array}{llllll}1 & 2 & 3 & 4 & 5 & 6\end{array}$

There is a decreasing scope of central control over digital initiatives.

$\begin{array}{llllll}1 & 2 & 3 & 4 & 5 & 6\end{array}$

We see increasing development costs for digital initiatives.

$\begin{array}{llllll}1 & 2 & 3 & 4 & 5 & 6\end{array}$

Average 4

How much is ambidexterity constrained by digital infrastructuring (Average of Average 1-4)?

How much is efficiency constrained by digital infrastructuring (Average of Average 1 and 3)?

How much is innovation constrained by digital infrastructuring (Average of Average 2 and 4)?

After filling in the self-assessment, the average of Average 1-4 will offer an indication of how existing digital infrastructuring practices are impacting the parallel attainment of efficiency and innovation (ambidexterity). Further, the ratio between the averages of Average 1 and 3 versus 2 and 4 will identify the current ambidextrous bias of digital infrastructuring, i.e. if digital infrastructuring primarily constrains efficiency or innovation.

Our recommendation is to use the self-assessment as a basis for internal dialogue and to carefully assess and discuss how existing practices may be sub-optimal, as a first step toward identifying and prioritizing how governance needs to change.

Corresponding author

Johan Magnusson can be contacted at: johan.magnusson@gu.se

For instructions on how to order reprints of this article, please visit our website: 